\title{
Imaging and photogrammetry models of Olduvai Gorge (Tanzania) by unmanned aerial vehicles: a high-resolution digital database for research and conservation of Early Stone Age sites
}

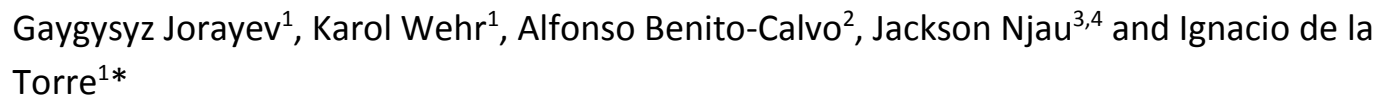

\section{* Corresponding author: i.torre@ucl.ac.uk}

${ }^{1}$ Institute of Archaeology, University College London, 31-34 Gordon Square, WC1H OPY, London, UK

${ }^{2}$ Centro Nacional de Investigación sobre la Evolución Humana (CENIEH), Paseo de la Sierra de Atapuerca 3, 09002 Burgos, Spain

${ }^{3}$ Department of Geological Sciences, Indiana University, 1001 East 10th Street, Bloomington, IN 47405-1405, U.S.A.

${ }^{4}$ The Stone Age Institute, 1392 W. Dittemore Rd., Gosport, IN 47433, U.S.A.

Abstract: This paper presents the first aerial mapping of Olduvai Gorge (Tanzania) using Unmanned Aerial Vehicles and photogrammetric techniques, to provide a detailed digital cartographic basis for this world-renowned paleoanthropological site. The survey covered an area of $32 \mathrm{~km}^{2}$ of Olduvai Gorge, and through the use of aerial photos and ground control points from Global Navigation Satellite Systems, an orthomosaic and Digital Surface Model, with a higher than $5 \mathrm{~cm} /$ pixel ground resolution, were produced. The Digital Surface Model was then denoised to calculate a Digital Elevation Model, and a high-resolution imaging model of Olduvai Gorge was generated. A preliminary morphometric characterization using Geographic Information Systems shows the potential of this approach when analysing multiple topographic variables in large areas of paleoanthropological relevance, including production of a new map template for Olduvai Gorge and new data for the investigation of sedimentary and tectonic processes. These results constitute one of the first attempts to obtain high quality imagery from large geographic areas amenable to Early Stone Age research, and introduce new workflows for the creation of Digital Elevation Models. Overall, the digital dataset produced is intended to support archaeological and geological investigation in this area, and provide new monitoring tools for the conservation of cultural heritage.

Keywords: Unmanned Aerial Vehicles; Olduvai Gorge; Paleoanthropology; Remote Sensing mapping; Digital Surface and Elevation Models 


\section{Introduction}

The potential of aerial imagery to locate, map and monitor paleontological and paleoanthropological resources has long been recognized (e.g. Remondino et al, 2010; Bates et al, 2008; Asfaw et al, 1990; Njau and Hlusko, 2010), in the wake of wider initiatives applying remote sensing to research in geographically large archaeological areas (Challis and Howard, 2006; Leckebusch, 2005; Hanson and Oltean, 2013; Comer and Harrower, 2013). In recent years, the fast-developing technology of Unmanned Aerial Vehicles (UAVs) has become common practice in archaeological research, assisting in the identification of sites and features not easily detected from the ground (Verhoeven, 2009; Casana et al, 2014; Chiabrando et al, 2011;). Aerial Archaeology has traditionally focused on late Prehistory or historical contexts in order to map buildings and structures (Al-kheder et al, 2009; Plets et al, 2012; Chiabrando and Spano, 2009; Hendrickx et al, 2011; Mozas-Calvache et al, 2012), but it can also be applied to Paleolithic research; digital files captured from UAV sensors (cameras and GPS) provide high-resolution still and motion imaging, which are the basis for the production of spatially geo-referenced 3D models, site mapping, analysis of site distribution patterns, determination of stratigraphic and geomorphological contexts, and recognition of sedimentary outcrops.

This study contributes to these initiatives by introducing an aerial imagery model for Olduvai Gorge (Tanzania), based on spatial datasets produced by UAVs and processed with photogrammetry techniques. Olduvai Gorge (Figure 1), a world renowned archaeological site, is exceptionally important for early human evolutionary research. It has a continuous history of investigation spanning over a century, during which comprehensive research has been undertaken on the paleoanthropology (e.g. L. Leakey et al, 1964; L. Leakey 1951, 1965; M. Leakey, 1971; M. Leakey and Roe, 1994) and geology (Hay, 1976) of the area. Nevertheless, despite continued investigations in the Gorge after the classic research period of the Leakeys and associates, the cartographic basis has remained poorly developed. In addition, Olduvai is not located in a region of the globe where there is extensive and continuous mapping; available topographic maps are outdated, have no openly accessible digital versions, are not particularly accurate, and free-access satellite imagery available for this area is of relatively low resolution. These caveats complicate the elaboration of high-resolution stratigraphic, geomorphological, paleogeographic and archaeological site maps, basic to paleoanthropological research and conservation management of the site which, together with Laetoli and the Ngorongoro Conservation Area, is listed as UNESCO World Heritage Site.

To overcome these issues, our aim was to develop a detailed digital cartographic basis for further spatial archaeological and geological investigations in Olduvai Gorge. The rapid development of relatively affordable UAV technologies provided an opportunity to produce accurate spatial datasets via aerial imaging of the current morphology of the Gorge. Given that the aim of the aerial survey was to generate georeferenced tiles of orthophotographs and Digital Terrain Models (DTMs), it also offered opportunities to analyse the landscape with much higher resolution than ever before, enabling a topographic as well as a remote sensing inspection of 
Olduvai Gorge. This paper aims to introduce the outcomes of our aerial survey, discuss the methodological challenges encountered, and present results and their potential applications for research and conservation in areas with paleoanthropological resources.

\section{Insert here Figure 1}

\section{Materials and Methods}

The aerial survey was undertaken with two types of UAV, a Swinglet CAM delta-wing platform and a DJI Phantom 2 Vision+ quadcopter (Figure 2). The Swinglet system, manufactured by SenseFly, has a rigid delta-wing (fixed-wing) EPP foam frame with one electric pusher motor, a specifically designed autopilot control unit and integrated camera (adapted version of Canon IXUS 220 HS 12.1 megapixel). It is piloted with a ground control unit (a rugged tablet running on Microsoft Windows), a remote controller and a radio modem for data link between the aerial vehicle and ground control unit. This UAV was used as the primary means of aerial survey imaging, where most flights were carried out in autopilot mode at altitudes around $120 \mathrm{~m}$ above ground level, with $4 \mathrm{~cm}$ per pixel ground resolution, 70\% longitudinal, and $70 \%-80 \%$ lateral overlap of images. The DJI quadcopter contained a 14-megapixel camera, was controlled with an Android tablet and supported by a GNSS receiver. Flights with the quadcopter were operated at a speed of $4 \mathrm{~m}$ per second at low altitudes (from 50 to $80 \mathrm{~m}$ above ground level), and produced a smaller coverage than the airplane, but resulted in a system that is more affordable to control and repair. Indeed, the use of UAVs in Olduvai Gorge proved to be logistically very challenging; dust, sand, rocks, wild fauna, and especially very strong winds and gusts, all caused significant difficulties during take-off, flight and landing. Any significant damage to the equipment could cause the season's programme to end, since receiving spare parts or online assistance was not an option due to the remote location of the site.

The Swinglet UAV flight patterns were designed with SenseFly's mission planning software. Images were georeferenced by combining them with the flight logs from the control station in Sense Fly's Postflight Suite software. This process allowed a certain level of automation, and georeferencing was relatively straightforward due to seamless integration of an on-board GPS receiver data into the Swinglet planning and control options. Fieldwork routine with the DJI Phantom quadcopter also required improvement in geolocation accuracy and addition of true elevation values, which are not included in geotagged photographs produced by the DJI drone. Thus, each mapping section was georeferenced with three control points; to insure that the method was non-invasive, reflective paper plates marked ground control points recorded with a high-accuracy GNSS receiver, which were then used to process the orthomosaic and surface models. Due to the limited range of the quadcopter, each mapping section required the launching of flights from both the northern and southern scarps, and in some cases, from the bottom of the Gorge too, in order to achieve adequate overlap. Each flight lasted an average of 15 minutes and covered a length of ca $300 \mathrm{~m}$ of the Gorge. 
121 The survey was carried out over four field seasons during 2013, 2014 and 2015 (Table 1). It 122 started from the so-called Junction Area, where the Main and Side Gorges meet (see Figure 1), 123 and expanded outwards from there. Although it varied depending on topographic and 124 atmospheric conditions, each flight covered on average an area of $120,000 \mathrm{~m}^{2}$ with the Swinglet system and $58,000 \mathrm{~m}^{2}$ with the quadcopter, at an average altitude respectively of 120 and $65 \mathrm{~m}$ above the departure point level. In total, $32,596,076 \mathrm{~m}^{2}$ of non-overlapping area within the region were photographed. From this total, 19,143,690 $\mathrm{m}^{2}$ were the Gorge itself, constituting $73.6 \%$ of the entire mapping area. Images were acquired with $4 \mathrm{~cm}$ per pixel ground resolution or higher. Due to the complexity of the landscape (with sharp elevation contrasts within small areas), very high overlapping (minimum of $70 \%$ longitudinal and $70 \%$ lateral) of orthogonal photographs was used for most flights.

Insert here Table 1

Orthogonal photographs obtained in each flight were processed with photogrammetric software developed by Pix4D. For certain areas where oblique and/ or ground level images were also available, PhotoScan software (Agisoft) was used as well. Resulting orthomosaics range in size from under $500 \mathrm{MB}$ to over $8.5 \mathrm{~GB}$, average at $2.7 \mathrm{~GB}$ and have a total size of $81.4 \mathrm{~GB}$. The large size of data files processed was a challenge in itself; it required a dedicated high power workstation, and on average 14 hours of processing time per tile. In order to georeference the photogrammetric models, we used non-invasive ground control points as described above, and also control points recorded from standing structures (e.g. buildings, concrete beacons) present throughout the Gorge. The final model showed errors from ca 0.5 to $1 \mathrm{~m}$ in longitude and latitude and up to $1.5 \mathrm{~m}$ in altitude, with a mean re-projection error of $>0.5$ pixel, and was overlapped onto a $60 \mathrm{~cm}$ resolution model provided by the DigitalGlobe Foundation.

In addition to orthomosaics, structure from motion processing produced point clouds used to calculate Digital Surface Models (DSM). The latter were transformed into Digital Elevation Models (DEM) after denoising vegetation, artificial structures and distortions which occurred during production of the orthomosaic. Denoising proved to be particularly time-consuming, since available algorithms (Sun et al, 2007; Stevenson et al, 2010) were either unsuitable for the size and precision of datasets, or not designed for a highly irregular surface (SAGA GIS DTM filter). Thus, algorithms automatizing the process had to be combined with manual editing of rasters. Due to dense vegetation in some areas of the gorge, the process was multi-stage, requiring removal of spikes in elevation caused by vegetation, cleaning up the bare earth raster and filling the gaps with Multilevel B-Spline Interpolation. Initial filtering employed the SAGA GIS slope based filter, removing cells with sharp slope changes and producing a bare earth raster. However, due to the substantial irregularity of the terrain at Olduvai Gorge, filtering had to be 
of vegetation and man-made structure cells were still present after the filter process. The bare earth model was subsequently imported into ArcGIS and a vector stencil created, which was used for clipping the model before importing it back into SAGA GIS for the interpolation stage.

\section{Insert here Table 2}

Filtering of DEMs from photogrammetric data was a major methodological challenge due to the large extent of the area surveyed, terrain roughness and vegetation density. Despite these issues, a comparison of six samples from varying terrain and vegetation densities (Figure 3, Table 2) shows that the denoising process established here was effective; changes in mean elevation are minimal while remaining higher in dense vegetation areas, which can be attributed to removal of peaks created by vegetation. Effectivity of the denoising method is evident in Sample \#1 (where no vegetation is present), as there is no change between the elevation of unfiltered and filtered models. Differences in aspect can also be associated with the removal of elevation spikes and the smoother character of the filtered DEM. In addition, all six samples returned desirable slope values, where the largest differences are expected; the main disparity observed is the low range of slope differences between unfiltered and filtered samples \#1, \#3 and \#5, where little to no vegetation exists. Significantly higher differences between slope values can be seen in samples \#2, \#4 and \#6, where change can be attributed to the removal of dense vegetation.

In summary, results of the comparison of the six samples confirm effectiveness of the denoising workflow presented in this paper, which shows a high degree of sensitivity to changes in types of terrain and levels of vegetation; most of the vegetation was filtered out in all cases, while not affecting the variability and underlying character of the terrain.

\section{Insert here Figure 3}

The resulting DEM provided a high-resolution dataset with which to characterize the morphometry of the mapping area. This characterization used standard GIS morphometric variables (elevation, slope, aspect, curvature), roughness calculation through the TRI index (Riley et al., 1999), and other variables such us depth, volume and drainage density. A depth map was created by subtracting the elevation of the Gorge itself from the interpolated flat surface, which simulates the area prior to erosion of the Gorge. The simulated flat surface was created with multilevel B-spline interpolation, focal statistics and low pass filters applied to smooth the surface by removing interpolation noise. The depth map was transformed into a volume map by multiplying depth values by cell area, showing the volume of sediment eroded in each cell.

\section{Results}

\subsection{Orthomosaic}


Production of a high quality orthomosaic of Olduvai Gorge was a major objective of this study. The resulting model provides a remarkably high-resolution digital aerial photographic repository, in which the orthomosaic cell size varies between 4 and $5.5 \mathrm{~cm}$ on the ground, covering over $32 \mathrm{~km}^{2}$ (Figure 4). As a result, our orthomosaic achieved XY precision of $<1 \mathrm{~m}$.

\section{Insert here Figure 4}

Application of the orthomosaic ranges from general cartographic outputs to specific research targets. For example, the UAV orthomosaic forms the foundation for a new outline of the map of Olduvai Gorge (Figure 5); bearing in mind that during the last five decades, virtually all publications have reproduced M. Leakey's (1971) and Hay's (1976) original maps, our Figure 5 provides not only a higher resolution of the outline of the Gorge, but also includes erosional changes in the landscape occurring in recent years. This template is made available in several formats in SOM 2-4.

With regard to more specific applications, the orthomosaic provides a high-resolution basis for geological mapping of Olduvai Gorge outcrops, both for field survey and remote sensing. As such, remote sensing classification of the RGB spectrum of the orthomosaic can be used to automatize identification of particular strata and lithologies, and shows great potential for largescale supervised classification of geological mapping at Olduvai.

\section{Insert here Figure 5}

\subsection{Digital Surface Model and Digital Elevation Model}

Automatization of the structure from motion workflow resulted in the generation of DSMs with the same error and precision as the orthomosaic described above. DSMs were filtered to obtain DEMs that could be applied to visual inspection and quantitative morphometrics of the Gorge. The process involved use of a highly customized DEM filter (see above), with calculations based on changes in slope (Figure 6A). Due to the processing requirements of substantially large datasets (the average size of a single DSM was 1.1 GB), DSMs (Figure 6B) were reduced to $20 \%$ of their original size. This resulted in a cell size of ca. $17.5 \mathrm{~cm}$ on the ground, although the original datasets (based on terrain models of $\mathrm{ca} .5 \mathrm{~cm}$ cell size) can be used for detailed analysis at any time. The resulting DEM of the entire area photographed is shown in Figure $\mathbf{6 C}$. 
Recent work has highlighted substantial differences in resolution between widely available imagery and that obtained from specific UAV initiatives (Fernández-Lozano and GutiérrezAlonso, 2016; Sadr, 2015). Thus, a comparative analysis of our UAV-produced DEM and the preexisting GDEM global model (with a $30 \mathrm{~m}$ resolution) was conducted to show the progress in resolution and accuracy. Results demonstrate the dramatic progress achieved in the mapping of the Gorge, showing an improvement of more than a hundredfold in the visual and quantitative understanding of topographic indicators. Thus, Table 3 shows that mean values of elevation and width differ considerably between the two models, which bear important consequences for calculations of Olduvai Gorge profiles (Figure 7).

\section{Insert here Table 3}

\section{Insert here Figure 7}

Differences are even more significant when erosion is estimated (Table 4); total sediment loss for the mapped area was calculated for the GDEM and compared to two Aerial DEM tiles, namely the Junction Area (where the highest density of early Pleistocene human fossils at Olduvai is concentrated), and the First Fault Area (where Olduvai Gorge ends and the Olduvai river discharges into the Olbalbal Depression). While estimates of the eroded area do not vary significantly between GDEM and UAV data (ranging from approx. $5 \%$ in the First Fault Area to $<1 \%$ for the entire mapping area), calculations of the total volume of sediment removed by erosion show substantially different results. Thus, the Aster model estimates erosion of ca. 887 million $\mathrm{m}^{3}$ of sediment, but the UAV imagery model reduces it to 586 million $\mathrm{m}^{3}$. The Junction Area and the First Fault Area (see Figure 8) show similar differences in ratios between the GDEM and UAV results, with disparities between the two models averaging 34\% (Table 4), once again highlighting the much higher quality of the new UAV imagery data.

\section{Insert here Table 4}

\subsection{Morphometric characterization of Olduvai Gorge}

Standard morphometric variables such as slope, elevation, aspect and curvature, as well as the TRI roughness index, are shown in Figure 9, and Figure $\mathbf{1 0}$ shows results of the depth, volume and drainage density models. The drainage network was calculated with flow direction and flow accumulation GIS tools, and used to estimate stream density, applying the line density tool at a search radius of $100 \mathrm{~m}$, and providing the length of lines per square metre of the surface. Stream order was used as a population field, assigning higher weight to streams of a higher order. The width of the Gorge was also calculated by measuring the distance from the northern to southern scarps across the mapping area. Scarp lines were converted into points and the distance from 
each point of the northern scarp to the nearest point on the southern scarp was calculated. The resulting set of distances gives the width of the Gorge throughout its length from West to East (Figure 11).

\section{Insert here Figure 9}

The mean elevation of the mapping area is $1418 \mathrm{~m}$ above the sea level (a.s.l.), with a mean slope of $12.8^{\circ}$. In general, the Main and Side Gorges are dominated by south facing hillslopes (171ㅇ), having mean and maximum depths of $35.33 \mathrm{~m}$ and $88.24 \mathrm{~m}$ respectively. These depths indicate mean and maximum volumes of $1.07 \mathrm{~m}^{3}$ and $2.68 \mathrm{~m}^{3}$ per cell respectively.

\section{Insert here Figure 10}

Morphometric variables show clear differences between the Main and the Side Gorges. This difference is associated with the greater incision of the Main Gorge, indicated by lower mean elevation, steeper slopes and deeper valleys (Table 5). The Side Gorge also shows mean curvatures closer to flat surfaces (curvature $=0$ ). Curvature ranges in the Main Gorge are higher, and connected with the more marked concavities and convexities in the Main Gorge, associated with scarps and the incision of lateral ravines. Overall, these features convey higher mean values of roughness for the Main Gorge. Lateral ravines are also more frequent in the mapping area of the Main Gorge, and indicated by a higher mean drainage density.

\section{Insert here Figure 11}

\section{Insert here Table 5}

The presence of lateral ravines determines variability in the width of the Gorge (Figure 11). Apart from this variability, width values in the Main Gorge show a general decreasing trend eastwards (downstream), although different patterns are discerned according to tectonic areas; width values are higher west of the Fifth Fault and between the Fourth and the Third faults, and narrower in the areas between the Fifth and the Fourth faults and between the Third and the First faults. On the other hand, width in the Side Gorge is defined by high values to the west, where there is an inflexion from a NW-SE to an E-W direction, just downstream from the small graben mapped by Hay (1976). To the east of this area, relatively constant low width values are shown as far as the FC- MNK outcrops: here, the highest values for the width of the Gorge are in the area affected by the FLK fault, just before the confluence with the Main Gorge. 
Morphometric variables also reveal different topographic patterns according to tectonic areas of the Main Gorge, which we defined in Figure 12 using the main faults described by Hay (1976). There is a logically decreasing trend downstream in mean elevation, but with slight variations. This decrease is more pronounced in areas 3 (located between the Fifth and the Fourth Fault) and 6 (First-Second faults), while in areas 2 (west of the Fifth Fault) and 4-5 (Fourth-Second fault), decrease in elevation is slower. Such variations are also observed in other variables. Mean slope shows the lowest values in area 3 (Fifth-Fourth faults), but increases drastically in area 4 (Fourth-Third faults), and reaches its highest values in area 5 (Third-Second faults). The Terrain Ruggedness Index (TRI) shows the same pattern, with lowest mean values in area 3 (Fifth-Fourth Fault) and maximum mean values in area 5 (Third-Second faults). Likewise, the shallowest values for mean depth are in area 3 (Fifth-Fourth Fault) and areas 6-7 (west of the Second Fault), while the deepest mean values are in area 2 (west of the Fifth Fault) and area 5 (Third-Second faults).

These variations also condition hillslope aspect. In areas 1, 4 (Fourth-Third faults) and 5 (ThirdSecond faults), mean vector values are at $180^{\circ}$ (southern orientation), while in areas 3 and 6-7, they vary slightly towards more SSE orientations. Mean values for general and plan curvature show a trough in area 6 (Second-First Faults), while the highest mean value for profile curvature is in this area. Mean values for drainage density increase slightly downstream and show little variation except for area 6 (Second-First Faults), where mean values increase notably due to the meandering pattern of the Olduvai Gorge channel in the proximity of the Olbalbal Basin.

Although further geomorphometric analysis is required, these topographic patterns may suggest that local differential uplift processes could have been more intense in area 5 , and to a lesser degree in areas 4 and 2, causing relief reactivation and intensification of erosional processes. Conversely, areas 3 and 6-7 tend to show characteristics associated with lower reliefs, indicating lower local differential uplift rates.

\section{Insert here Figure 12}

\section{Discussion and conclusions}

Our results show that UAV photography can be used to produce affordable high-resolution maps in large geographic areas of archaeological relevance. Data derived from aerial photography show a notable increase in detail when compared to widely accessible satellite imagery (GDEM, $30 \mathrm{~m}$ resolution), and with the use of a GNSS receiver, the geolocation of the combined DEM is highly accurate (ca. $17.5 \mathrm{~cm}$ resolution with $<1 \mathrm{~m}$ precision). This high-resolution imagery and elevation data facilitates production not only of better quality conventional cartographic outputs (e.g. aerial photographs and topographic maps), but also enables detailed quantitative analysis of the Olduvai Gorge landscape.

Total station (TST) surveys are still useful for recording the location of archaeological finds in individual trenches and across nearby outcrops at Olduvai (de la Torre et al, 2015), but georeferenced and multicolour (typically RGB) UAV orthomosaics also have a clear advantage over monochrome point clouds recorded with TST or Global Navigation Satellite System (GNSS) 
receivers. Using GNSS ground control points, georeferencing of UAV orthophoto tiles can achieve similar levels of accuracy as TST or GNSS surveys. Furthermore, georeferenced aerial orthomosaics offer a more realistic representation of the areas mapped, and achieve a far larger regional coverage than ground-based methods.

While the use of UAVs for photogrammetric reconstructions of archaeological site plans is becoming widespread (e.g. De Reu et al, 2013; de Reu et al, 2014; Pollefeys et al, 2003; Verhoeven et al, 2012; Williams, 2012; Fernandez-Hernandez et al, 2015), the regional (rather than site-specific) digital imagery dataset we have produced for Olduvai Gorge provides a highresolution cartographic database, which can be used to conduct further archaeological, geological, conservation, and outreach studies in ways as yet unexplored. Thus, aerial photographs, orthophotomaps and DEMs provide basic stereoscopic and quantitative morphometric data that help identify the sequence and extension of landforms involved in the incision of the Gorge, and their relationships with tectonic and/or climatic events. Detailed geological mapping from DEM and imagery can also be used to define the extension, geometry and thickness of sedimentary beds at Olduvai. Due to the centimetric resolution of our imagery and DEM, even small features such as tephra layers are amenable to mapping. These initiatives can be explored with the aid of supervised and unsupervised multiband classifications, but also through classic field mapping techniques. They will help to better understand and quantify paleogeographic settings and the tectonic history of the Olduvai basin, which shaped Early Stone Age hominin landscapes and adaptations.

In summary, our workflow for the production of DEMs from large, high-resolution structure from motion surface models, provides a useful framework for application in similarly irregular terrains, where standard denoising algorithms and filters are not sufficient or suitable to achieve an accurate recording of topographic features. Furthermore, our DEM and high-resolution imagery provide a powerful tool to accurately position the location of hominin and archaeological discoveries at Olduvai, and map new paleoanthropological resources, thus enabling a detailed regional spatial analysis of archaeological data. In addition, hydrological and slope models derived from the DEM can assist in calculating soil erosion models (e.g. RUSLE). As one of the most important paleoanthropological sites in the World and home to numerous iconic hominin fossils (Tobias, 1967, 1991), many discovered on the surface of eroded outcrops (Leakey, 1978; Day, 1977), the study of erosional processes at Olduvai Gorge, as shown by the test results discussed in this paper show, is essential in initiating a monitoring conservation programme of the site and may also be used to predict and estimate the loss of fossils to date.

In summary, this study (one of the first to apply UAV methods to paleoanthropological localities, and apply such techniques to large geographic areas of archaeological interest), shows the potential of high-resolution aerial photogrammetry for cartographic, geological and spatial analysis surveys in archaeology, and opens new avenues for remote sensing GIS studies in human evolutionary research.

\section{Acknowledgements}


We are grateful to the Olduvai Geochronology Archaeology Project (OGAP) and the Ancient Merv Project for logistical and research assistance, and to Jonathan Reeves for his contribution during fieldwork. We also thank Pix4D and the DigitalGlobe Foundation for their support. Funding from UCL Qatar and the European Research Council-Starting Grants (ORACEAF project: 283366) are gratefully acknowledged. Research at Olduvai Gorge was authorized by COSTECH, the Tanzanian Department of Antiquities, and the Ngorongoro Conservation Area Authority.

\section{References}

Al-kheder, S., Al-shawabkeh, Y., Haala, N. (2009). Developing a documentation system for desert palaces in Jordan using 3D laser scanning and digital photogrammetry. Journal of Archaeological Science 36 (2), 537-546.

Asfaw, B., Ebinger, C., Harding, D., White, T. D. \& WoldeGabriel, G. (1990). Space-based Imagery in Paleoanthropological Research: An Ethiopian Example. National Geographic Society Research $6,418-434$.

Bates, K.T., Rarity, F., Manning, P.L., Hodgetts, D., Villa, B., Oms, O. \& Gawthorpe, R.L. (2008). High-resolution LiDAR and photogrammetric survey of the Fumanya dinosaur tracksites (Catalonia): implications for the conservation and interpretation of geological heritage sites. Journal of the Geological Society, London 165, 115-127.

Casana, J., Kantner, J., Wiewel, A. \& Cothren, J. (2014). Archaeological aerial thermography: a case study at the Chaco-era Blue J community, New Mexico. Journal of Archaeological Science 45, 207-219.

Challis, K. \& Howard, A. J. (2006). A review of trends within archaeological remote sensing in alluvial environments. Archaeological Prospection 13, 231-240.

Chiabrando, F., Nex, F., Piatti, D. \& Rinaudo, F. (2011). UAV and RPV systems for photogrammetric surveys in archaeological areas: two tests in the Piedmont region (Italy). Journal of Archaeological Science 38, 697-710.

Chiabrando, F. \& Spanò, A. (2009). Digital wide scale orthoprojections and mapping from lowheight aerial images. Journal of Cultural Heritage 10, Supplement 1, e49-e58.

Comer, D.C \& Harrower, M.J. (2013). Mapping Archaeological Landscapes from Space. New York: Springer.

Day, M. H. (1977). Guide to Fossil Man. A Handbook of Human Palaeontology. London: Cassell, Third Edition.

De Reu J., De Smedt P., Herremans D., Van Meirvenne M., Laloo P., De Clercq W. (2014). On introducing an image-based 3D reconstruction method in archaeological excavation practice. Journal of Archaeological Science 41, 251-262. 
De Reu J., Plets G., Verhoeven G., De Smedt P., Bats M., Cherretté B., De Maeyer W., Deconynck J., Herremans D., Laloo P., Van Meirvenne M., De Clercq W. (2013). Towards a three-dimensional cost-effective registration of the archaeological heritage. Journal of Archaeological Science 40 (2), 1108-1121.

Fernández-Hernandez, J., González-Aguilera, D., Rodríguez-Gonzálvez, P. \& Mancera-Taboada, 428 J. (2015). Image-Based Modelling from Unmanned Aerial Vehicle (UAV) Photogrammetry: An 429 Effective, Low-Cost Tool for Archaeological Applications. Archaeometry 57, 128-145.

Fernández-Lozano, J. \& Gutiérrez-Alonso, G. (2016). Improving archaeological prospection using localized UAVs assisted photogrammetry: An example from the Roman Gold District of the Eria River Valley (NW Spain). Journal of Archaeological Science: Reports 5, 509-520.

Hanson, W. S., Oltean, I. A. \& eds. (2013). Archaeology from Historical Aerial and Satellite Archives. New York: Springer.

Hay, R. L. (1976). Geology of the Olduvai Gorge. Berkeley: University of California Press.

Hendrickx, M., Gheyle, W., Bonne, J., Bourgeois, J., De Wulf, A., Goossens, R. (2011). The use of from the Tuekta burial mounds in the Russian Altay. Journal of Archaeological Science 38 (11), 2968-2978.

Leakey, L. S. B. (1951). Olduvai Gorge. A Report On The Evolution Of The Hand-Axe Culture In Beds I-IV. Cambridge, Cambridge University Press.

442 Leakey, L. S. B. (1965). Olduvai Gorge 1951-61. Volume 1. A preliminary report on the geology 443 and fauna. Cambridge: Cambridge University Press.

444 Leakey, L. S. B., Tobias, P. V. \& Napier, J. R. (1964). A New Species of the Genus Homo from 445 Olduvai Gorge. Nature 202, 5-7.

446 Leakey, M. D. (1971). Olduvai Gorge. Vol 3. Excavations in Beds I and II, 1960-1963. Cambridge: 447 Cambridge University Press.

448 Leakey, M. D. (1978). Olduvai fossil hominids: their stratigraphic positions and associations. In 449 (C. Jolly, Ed.) Early Hominids from Africa. London: G. Duckworth \& Co, 3-16.

450 Leakey, M. D. \& Roe, D. A. (1994). Olduvai Gorge. Volume 5. Excavations in Beds III, IV and the 451 Masek Beds, 1968-1971. Cambridge: Cambridge University Press.

452 Leckebusch, J. (2005). Aerial archaeology: a full digital workflow for aerial photography. 453 Archaeological Prospection 12, 235-244.

454 Mozas-Calvache, A. T., Pérez-García, J. L., Cardenal-Escarcena, F. J., Mata-Castro, E. \& Delgado455 García, J. (2012). Method for photogrammetric surveying of archaeological sites with light aerial 456 platforms. Journal of Archaeological Science 39, 521-530. 
Njau, J. K. \& Hlusko, L. J. (2010). Fine-tuning paleoanthropological reconnaissance with highresolution satellite imagery: the discovery of 28 new sites in Tanzania. Journal of Human Evolution 59, 680-684.

Plets, G., Gheyle, W., Verhoeven, G., De Reu, J., Bourgeois, J., Verhegge, J., Stichelbaut, B. (2012). Towards a three-dimensional registration of the archaeological heritage of the Altai Mountains. Antiquity 86 (333), 884- 897.

Pollefeys, M., Van Gool, L., Vergauwen, M., Cornelis, K., Verbiest, F., Tops, J. (2003). 3D recording for archaeological fieldwork. Computer Graphics and Applications, IEEE 23 (3), 20-27.

Remondino, F., Rizzi, A., Girardi, S., Petti, F.M., Avanzini, M., 2010. 3D Ichnology - recovering digital 3D models of dinosaur footprints. The Photogrammetric Record 25 (131), 266-282. Topographic Heterogeneity. Intermountain Journal of Sciences 5 (1-4), 23-27.

Sadr, K. (2015). A Comparison of Accuracy and Precision in Remote Sensing Stone-walled Structures with Google Earth, High Resolution Aerial Photography and LiDAR; a Case Study from the South African Iron Age. Archaeological Prospection n/a-n/a.

Stevenson, J.A., Sun, X., Mitchell, N.C. (2010). Despeckling SRTM and other topographic data with a denoising algorithm. Geomorphology 114, 238-252. Mesh Denoising. IEEE Transaction on Visualisation and Computer Graphics 13 (5), 925-938. boisei. Cambridge: Cambridge University Press.

Tobias, P. V. (1991). Olduvai Gorge. Volume 4. The skulls endocasts and teeth of Homo habilis. Cambridge: Cambridge University Press. Ed.) Métodos y técnicas para la recuperación del registro arqueológico: una mirada desde el presente. Barcelona: Treballs d'Arqueologia, 20, 21-40.

484 Verhoeven, G. J. J. (2009). Providing an archaeological bird's-eye view - an overall picture of 485 ground-based means to execute low-altitude aerial photography (LAAP) in Archaeology. Archaeological Prospection 16, 233-249.

490 Williams, T. (2012). Unmanned Aerial Vehicle Photography: Exploring the Medieval City of Merv, 491 on the Silk Roads of Central Asia. Archaeology International 15, 74-88. 